\title{
Prevalence of malocclusion and its associated factors among pre- schoolchildren in Kinondoni and Temeke Districts, Tanzania
}

MATILDA MTAYA ${ }^{*}$, PONGSRI BRUDVIK ${ }^{2}$ and ANNE N. ASTROM ${ }^{2}$

${ }^{1}$ Muhimbili University of Health and Allied Sciences, Department of Orthodontics Paedodontics and Community Dentistry, School of Dentistry, Dar es Salaam, Tanzania

${ }^{2}$ University of Bergen, Bergen, Norway

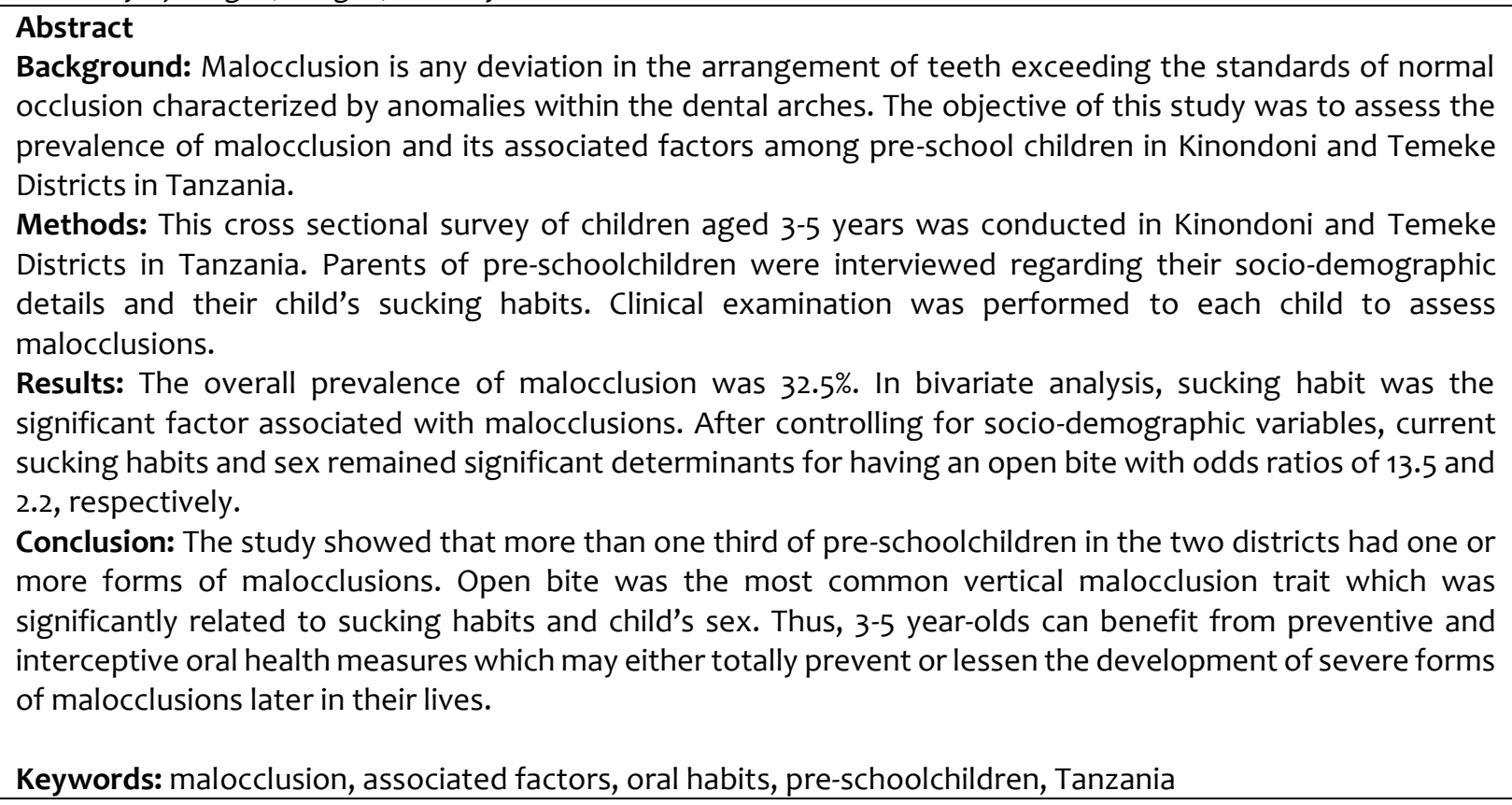

\section{Introduction}

Malocclusion is any deviation in the arrangement of teeth exceeding the standards of normal occlusion (Thilander \& Rønning, 1995). It may be characterized by anomalies within the dental arches, malrelation of dental arches and skeletal facial discrepancies (Proffit et al., 2012). The prevalence of malocclusions in different populations have been reported by many studies (al-Emran et al., 1990; Ng'ang'a et al., 1996; Thilander et al., 2001; Onyeaso, 2004; Malandris \& Mahoney, 2004; Ciuffolo et al., 2005; Josefsson et al., 2007; Carvalho et al., 2011; Dimberg et al., 2010; Krishna et al., 2013). The reported prevalence of malocclusions in pre-schoolchildren with mainly primary teeth varies between 20 and over 70 \% (Malandris \& Mahoney, 2004; Carvalho et al., 2011; Dimberg et al., 2011; Krishna et al., 2013). The prevalence variance depends on the population studied, ethnic differences, criteria used for scoring malocclusions, wide ranges in number of participants and age range of participants examined (Thilander et al., 2001; Malandris \& Mahoney, 2004; Abu Alhaija et al., 2005; Dimberg et al., 2010; Carvalho et al., 2011; Krishna et al., 2013).

The impact of a malocclusion is that it can cause psychological and social problems mainly related to impaired dental and facial aesthetics (Kenealy et al., 1989). But also, a malocclusion can cause alterations in oro-facial structures (Larsson, 1994; Øgaard et al., 1994; Fukuta et al., 1996;

\footnotetext{
* Correspondence E-mail: matildamtaya@yahoo.com
} 
Viggiano et al., 2004; Poyak, 2006; Proffit et al., 2012) with adverse oro-facial health effects such as increase in susceptibility to dental caries (Stahl \& Grabowski, 2004).

It is generally acknowledged that malocclusions are developmental conditions that result from an interplay of genetic and environmental aetiological factors (Thilander \& Rønning, 1995). A combination of both factors has often been found in the same individual (Mitchell, 2007). The environmental factors that have been implicated with the development of malocclusions include but not limited to early removal of primary teeth, dental caries experience and trauma to primary teeth (Thilander \& Rönning, 1995). Some studies have also identified oral health related behaviours such as oral habits as substantial malocclusion influencing factors. They include thumb sucking habits, finger sucking habits and pacifier or dummy sucking (Katri et al., 2003; Proffit et al., 2012). Other unfavourable habits are lips sucking or tongue thrusting (Larsson, 1994; Poyak, 2006). Earlier studies have further indicated that these habits can be influenced by sex of the child, birth rank/order of birth of a child, socio-economic status and level of parents' education (Larsson et al., 1992; Farsi \& Salama, 1997; Warren et al., 2000). The effects of unfavourable oral habits on oro-facial structures including untoward dental occlusion change have also been documented (Larsson, 1994; Thilander et al., 1995; Adair et al., 1995; Farsi \& Salama, 1997; Kerosuo, 2002; Proffit et al., 2012; Varas et al., 2012). Specifically, finger sucking habits have significantly been associated with development of an anterior open bite, increased overjet, Class II canine relationship and posterior cross-bite (Larsson, 1994; Ogaard et al., 1994; Fukuta et al., 1996; Viggiano et al., 2004; Poyak, 2006; Proffit et al., 2012). Nonetheless, some studies have shown inconclusive results regarding the effects of oral habits on one's occlusion (Farsi \& Salama, 1997; Warren \& Bishara, 2002). Despite the magnitude and public importance of this condition, there is dearth of information on malocclusions and associated factors among children in Tanzania. Therefore, this study was conducted to assess the prevalence of malocclusion and its associated factors in Kinondoni and Temeke Districts of eastern Tanzania.

\section{Materials and Methods}

\section{Study area and design}

This cross sectional study was conducted among pre-schools of Kinondoni and Temeke districts in Dar es Salaam City in Tanzania. Dar es Salaam is the largest and most socially and culturally heterogenic City in Tanzania. Kinondoni and Temeke districts were selected for the study. The districts are diverse in terms of their socio-demographic profile, with Kinondoni having higher employment rates, literacy rates and proportions of the population using the most expensive form, electricity, as their main source of energy for cooking. Study participants were obtained from a census of 3-5-year-olds attending 8 selected pre-schools in Kinondoni district ( 5 pre-schools) and Temeke district ( 3 preschools). A total of 253 of 305 eligible pre-school children and their parents participated in the survey, making the response rate of $83 \%$.

\section{Data collection}

A face-to-face structured interview involved parents/caregivers of the 3-5-year-old pre-school children in a classroom setting. A pre-tested questionnaire in Kiswahili language was used. It included questions on socio-demographic characteristics and children's sucking habits. Socio-demographics were assessed in terms of district (Kinondoni/Temeke), sex, age, parental education and number of rooms in their houses. History of sucking was assessed by asking the parents whether their children had ever sucked thumb/finger, tongue or lip. Current sucking habit was assessed by asking the parents if their children had any sucking habits currently.

Clinical examinations were done in a classroom setting with natural daylight as the source of illumination. The children were clinically examined for malocclusions in the presence of their 
parents/caregivers (after their parents had completed the interview). The registration criterion was according to Björk et al. (1964) with some modifications by al-Emran et al. (1990). Absence/ presence of the following recordings was also examined: a maxillary overjet, a mandibular overjet, a Class II/Class III molar occlusion, an open bite, a deep bite, a lateral cross-bite, a midline shift, crowding and spacing. Occlusion in the anterior segment could not always be determined in pre-school children due to shedding of their primary incisors. Such cases were then excluded for overjet and overbite analyses, but were included in the analyses of other malocclusions. A sum score of malocclusions (SMO) was constructed to provide the overall prevalence of malocclusion, based on the diagnosis of absence/ presence a maxillary overjet, a mandibular overjet, a Class II/Class III molar occlusion, an open bite, a deep bite, a lateral cross bite, a midline shift, crowding and spacing.

\section{Data analysis}

Data was analysed using the Statistical Package for Social Sciences version 16.0 (SPSS Inc., Chicago, Illinois, USA). Frequencies were generated to assess percentage distribution/prevalence of different variables. Cross tabulations and Chi-square statistics were used to assess bivariate relationships. Multivariate analysis was conducted using multiple logistic regression analysis. The $\mathrm{p}$-value for statistical significance was set at $\mathrm{p}<0.05$.

\section{Ethical considerations}

Ethical clearance was obtained from the Research and Publication Committee of the Muhimbili University of Health and Allied Sciences. Permission to work with pre-school children was obtained from Kinondoni and Temeke municipalities, their respective educational authorities, schools administrations and parents. Only those pre-school children whose parents provided either verbal and written consents participated in the study.

\section{Results}

A total of 253 pre-school children mean age $=5$ years in eight pre-schools participated in the study. The overall prevalence of malocclusion (i.e. SMO>0 - having any type of a malocclusion) was $32.5 \%$. The majority (90.9\%) of the children showed Class I molar relationship. Class II and Class III were registered among $0.8 \%$ and $8.3 \%$ of the children, respectively. The most frequently recorded anomalies were spacing of at least $2 \mathrm{~mm}$ (19.8\%) and open bite (18.6\%). Overall, various malocclusion traits, including open bite, were identified slightly more in girls than in boys $(p>0.05)$. There was no significant difference with respect to malocclusion traits between the district of residence of the pre-school children (Table 1).

As regards to sucking habits (Table 2), $28 \%$ of the pre-school children had a history of sucking habits. Thumb/finger sucking habits were the most common form of habits, reported among $20.9 \%$ of the pre-schoolchildren. Current sucking habits were reported among $19 \%$ of the children. Regarding association between malocclusions and related environmental factors, open bite was a single malocclusion trait that was statistically significantly associated with sucking habits (Table 3).

Pre-school children with a history of sucking habits had statistically significantly more open bite registered than children without such a history $(p<0.001)$. Similarly, pre-school children with current sucking habits were diagnosed with open bite more often than pre-school children with absence of such habits ( $p<0.001)$. After controlling for socio-demographic variables, only current sucking habits and sex remained as strong determinants for an open bite with the odds ratios of 13.5 and 2.2, respectively (Table 3). 
Table 1. Percentages (\%) and number ( $n$ ) of occlusal and space characteristics among pre-school children by district and sex

\begin{tabular}{|c|c|c|c|c|c|c|}
\hline & & \multicolumn{2}{|l|}{ District } & \multicolumn{2}{|l|}{ Sex } & \multirow{2}{*}{$\begin{array}{l}\text { Total } \\
\%(n)\end{array}$} \\
\hline & & $\begin{array}{l}\text { Kinondoni } \\
\%(\mathrm{n})\end{array}$ & $\begin{array}{l}\text { Temeke } \\
\%(\mathrm{n})\end{array}$ & $\begin{array}{l}\text { Boys } \\
\%(n)\end{array}$ & $\begin{array}{l}\text { Girls } \\
\%(\mathrm{n})\end{array}$ & \\
\hline \multicolumn{7}{|l|}{ Occlusion } \\
\hline \multirow[t]{8}{*}{ Sagittal } & Molar relationship & & & & & \\
\hline & Class I & $92.1(163)$ & $88.2(67)$ & $91.8(123)$ & $89.9(107)$ & $90.9(230)$ \\
\hline & Class II & $1.1(2)$ & $o(0)$ & $o(0)$ & $1.7(2)$ & $0.8(2)$ \\
\hline & $\begin{array}{l}\text { Class III } \\
\text { Maxillary overjet }\end{array}$ & $6.8(12)$ & $11.8(9)$ & $8.2(11)$ & $8.4(10)$ & $8.3(21)$ \\
\hline & $1-4.9 \mathrm{~mm}$ & $68.4(121)$ & $59.2(45)$ & $67.9(91)$ & $63(75)$ & $65.6(166)$ \\
\hline & $5-8.9 \mathrm{~mm}$ & $o(0)$ & $3.9(3)$ & $1.5(2)$ & $0.8(1)$ & $1.2(3)$ \\
\hline & $\begin{array}{l}n / a \\
\text { Mandibular overjet }\end{array}$ & $31.6(56)$ & $36.8(28)$ & $30.6(41)$ & $36.1(43)$ & $33.2(84)$ \\
\hline & $<0-1.9 \mathrm{~mm}$ & $6.8(12)$ & $2.6(2)$ & $6(8)$ & $5(6)$ & $5 \cdot 5(14)$ \\
\hline \multirow[t]{7}{*}{ Vertical } & Overbite & & & & & \\
\hline & $0.1-2.9 \mathrm{~mm}$ & $63.3(111)$ & $55 \cdot 3(42)$ & $63.4(85)$ & $58(68)$ & $60.9(153)$ \\
\hline & $3-4.9 \mathrm{~mm}$ & $5.6(10)$ & $7.9(6)$ & $6(8)$ & $6.7(8)$ & $6.3(16)$ \\
\hline & $\mathrm{n} / \mathrm{a}$ & $31.6(56)$ & $36.8(28)$ & $30.6(41)$ & $36.1(43)$ & $33.2(84)$ \\
\hline & Open bite & & & & & \\
\hline & $0-1.9 \mathrm{~mm}$ & $18.1(32)$ & $10.5(8)$ & $13.4(18)$ & $18.5(22)$ & $15.8(40)$ \\
\hline & $\geq 2 \mathrm{~mm}$ & $3.4(6)$ & $1.3(1)$ & $1.5(2)$ & $4.2(5)$ & $2.8(7)$ \\
\hline \multirow[t]{6}{*}{ Transversal } & Cross bite & & & & & \\
\hline & Absent & $98.9(175)$ & $98.7(75)$ & $100(134)$ & $97.5(116)$ & $98.8(250)$ \\
\hline & Present & $1.1(2)$ & $1.3(1)$ & $o(0)$ & $2.5(3)$ & $1.2(3)$ \\
\hline & Midline shift & & & & & \\
\hline & Absent $(<2 \mathrm{~mm})$ & $92.7(164)$ & $90.8(69)$ & $92.5(124)$ & $91.6(109)$ & $92.1(233)$ \\
\hline & $\geq 2 \mathrm{~mm}$ & $7 \cdot 3(13)$ & $9.2(7)$ & $7.5(10)$ & $8.4(10)$ & $7.9(20)$ \\
\hline \multirow[t]{3}{*}{ Space anomalies } & Absent (or $<2 \mathrm{~mm}$ ) & $81.4(144)$ & $75(57)$ & $80.6(108)$ & $78.2(93)$ & $79.4(201)$ \\
\hline & Crowding ( $\geq 2 \mathrm{~mm}$ ) & $1.1(2)$ & $o(0)$ & $0.7(1)$ & $0.8(1)$ & $0.8(2)$ \\
\hline & Spacing ( $\geq 2 \mathrm{~mm})$ & $17.5(31)$ & $25(19)$ & $18.7(25)$ & $21(25)$ & $19.8(50)$ \\
\hline
\end{tabular}

Table 2. Prevalence of different types of sucking habits among pre-school children

\begin{tabular}{lll}
\hline Sucking habits & Number $(\mathbf{n})$ & Percentage $(\%)$ \\
\hline History of sucking habits & 71 & 28 \\
Thumb/finger & 53 & 20.9 \\
Tongue & 13 & 5.1 \\
Lip/s & 5 & 2 \\
Current sucking habits & 48 & 19 \\
\hline
\end{tabular}


Table 3. Factors associated with presence of open bite among pre-schoolchildren

\begin{tabular}{llll}
\hline Variable & Response & Number (Percentage) & Adjusted OR (95\%Cl) \\
\hline District & Kinondoni & $38(21.5)$ & 1 \\
& Temeke & $9(11.8)$ & $0.5(0.2-1.3)$ \\
Sex & Male & $20(14.9)$ & 1 \\
\multirow{2}{*}{ Ever sucking } & Female & $27(22.7)$ & $2.2(1.1-4.7)^{*}$ \\
& Yes & $27(38.0)^{* *}$ & 1 \\
Current sucking & No & $20(11.0)$ & $0.9(0.2-3.7)$ \\
& Yes & $26(55.3)^{* *}$ & 1 \\
& No & $21(10.2)$ & $13.5(3.3-55.4)^{* *}$ \\
\hline
\end{tabular}

Multivariate logistic regression: Chi-square, adjusted odds ratios (OR) and $95 \%$ confidence intervals (Cl); \%=percentages, $\mathrm{n}=$ number of pre-schoolchildren); ${ }^{*}<0.05,{ }^{* *} \mathrm{p}<0.001$

\section{Discussion}

The total prevalence of malocclusion ( $\mathrm{SMO}>0$ ) among pre-school children presented in this study was lower than that reported among children in the United States (Trottman \& Elsbach, 1996), Germany (Robke, 2008), Sweden (Dimberg et al., 2010) and Lithuania (Kasparaviciene et al., 2014). However, it was much higher than that reported by previous studies in Tanzania (Kerosuo et al., 1991; Mugonzibwa et al., 2004). Methods of malocclusion registration and age ranges of children involved in the studies could be important factors explaining these differences (Kasparaviciene et al., 2014; Wagner \& Heinrich-Weltzien, 2015). In our study, spacing of at least $2 \mathrm{~mm}$ and open bite were the most common traits. This finding was similar to what was reported by Dimberg et al. (2010) and Kasparaviciene et al. (2014) in their studies among Swedish and Lithuanian children, respectively. Conversely, the results did not conform to the findings by Zhou et al. (2016) in a study among Chinese children.

Similar to the findings by Kasparaviciene et al. (2014) and Zhou et al. (2016) there was no significant difference in the occurrence of most occlusal traits between boys and girls among our study participants. However, girls had slightly more of different malocclusion traits than boys. The reason for this could be due to the role of sucking habits; these were reported to be performed more by girls than by boys. Sucking habits have been found to be associated with numerous occlusal problems in children (Farsi \& Salama, 1997; Onyeaso \& Sote, 2001; Dimberg et al., 2010; Warren et al., 2005; QuashieWilliams et al., 2010; Zhou et al., 2016). In this study therefore, the sucking habits were behaviours of interest that were significantly associated with one of the commonest malocclusion trait (open bite). Pre-school children, whoever performed these kinds of behaviours, comprised over a quarter of all the children. This proportion was lower than that reported by Dimberg et al. (2010) and higher than that reported among Nigerian children of similar age group (Onyeaso \& Sote 2001; Onyeaso et al., 2002). Specifically, this study found that finger sucking habit was the commonest type of unfavourable sucking behaviour. In contrast, finger sucking was reported as the least common type of oral habits in a study in Lithuania (Kasparaviciene et al. (2014) while Dimberg et al. (2010) found dummy sucking to be a dominant non-nutritive sucking habit among Swedish children. Dummy sucking is usually not a common practice among Tanzanian children.

Noteworthy, open bite was a single malocclusion trait that was associated with sucking habits in this study. This finding is supported by earlier studies which provided evidence of a positive relationship between sucking habits and being detected with an open bite (Farsi \& Salama, 1997; Warren et al., 2005; Dimberg et al., 2010; Wagner \& Heinrich-Weltzien, 2015). It is also important to take into account that the prevalence of open bite in pre-school children in the current study might have been underestimated due to elimination in the analysis of 3-5-year-olds who had their primary incisors shed. Results on the extent, associated factors and distribution of malocclusions clearly suggests a 
need for developing preventive and interceptive orthodontic programs among pre-school children. In view of the relatively scarce resources that are available for oral health care services in Tanzania, emphasis should be put on oral health education to oral health professionals (in terms of continuing education) and parents/caregivers. Moreover, intervention programmes to pre-school children (such as interceptive orthodontics) should also be considered. In doing so, malocclusions related to environmental factors (such as sucking habits) can be timely altered and children's occlusal, psychosocial as well as overall oral health status can be considerably improved.

The findings of this study are likely to have some limitations. The study might have been subjected to sources of error, biasing the results and a conclusion drawn. The bias could be in terms of a systematic error which might have occurred as a results of selection bias from the participants' end (e.g. non response) and as information bias or misclassification related to the information collected from the participants. To minimize such kind of biases, interviews with parents in this study were done before examining their children clinically.

In conclusion, the prevalence of having any malocclusion ( $\mathrm{SMO}>0$ ) in 3-5-year-olds in Kinondoni and Temeke District in Tanzania was 32.5\%. Sucking habits and sex are important risk indicators of malocclusion. Thus, preventive and interceptive orthodontic programmes are highly recommended in pre-school children.

\section{Competing interests}

The authors declare that they have no competing interests.

\section{Authors' contributions}

MM conceived the idea, designed the study, collected data, carried out statistical analysis and wrote the first draft of the manuscript. PB participated in the study design, methodology and manuscript writing. AA designed the study, carried out statistical analysis. All read and approved the final version of the manuscript.

\section{Acknowledgements}

This study was financially supported by the Faculty of Dentistry and the Centre for International Health, University of Bergen and Statens Lånakassen, Norway. The authors would like to thank the Kinondoni and Temeke Municipal authorities, Schools administrations and Muhimbili University of Health and Allied Sciences for giving permission to conduct this study. We are grateful to the parents/guardians of pre-school children who participated in this study.

\section{References}

Abu Alhaija, E.S., Al-Khateeb, S.N. \& Al-Nimri, K.S. (2005) Prevalence of malocclusion in 13-15-yearold North Jordanian school children. Community Dental Health 22: 266-271.

Adair, S.M., Milano, M., Lorenzo, I. \& Russel, C. (1995) Effects of current and former pacifier use on the dentition of 24- to 59-month-old children. Pediatric Dentistry 17: 437-444.

Al-Emran, S., Wisth, P.J. \& Bøe, O.E. (1990) Prevalence of malocclusion and need for orthodontic treatment in Saudi Arabia. Community Dentistry and Oral Epidemiology 18: 253-255.

Björk, A., Krebs, A. \& Solow, B. (1964) A method for epidemiological registration of malocclusion. Acta Odontologica Scandinavica 22: 27-41. 
Carvalho, A.C., Paiva, S.M., Scarpelli, A.C., Viegas, C.M., Ferreira, F.M. \& Pordeus, I.A. (2011) Prevalence of malocclusion in primary dentition in a population-based sample of Brazilian preschool children. European Journal of Paediatric Dentistry 12: 107-111.

Ciuffolo, F., Manzoli, L., D'Attilio, M., Tecco, S., Muratore, F., Festa, F. \& Romano, F. (2005) Prevalence and distribution by gender of occlusal characteristics in a sample of Italian secondary school students: a cross-sectional study. European Journal of Orthodontics 27: 601-606.

Dimberg, L., Bondemark, L., Söderfeldt, B. \& Lennartsson, B. (2010) Prevalence of malocclusion traits and sucking habits among 3-year-old children. Swedish Dental Journal 34: 35-42.

Farsi, N.M. \& Salama, F.S. (1997) Sucking habits in Saudi children: prevalence, contributing factors and effects on the primary dentition. Pediatric Dentistry 19: 28-33.

Fukuta, O., Braham, R.L., Yokoi, K. \& Kurosu, K. (1996) Damage to the primary dentition resulting from thumb and finger (digit) sucking. ASDC Journal of Dentistry for Children 63: 403-407.

Josefsson, E., Bjerklin, K. \& Lindsten, R. (2007) Malocclusion frequency in Swedish and immigrant adolescents--influence of origin on orthodontic treatment need. European Journal of Orthodontics 29: 79-87.

Kasparaviciene, K., Sidlauskas, A., Zasciurinskiene, E., Vasiliauskas, A., Juodzbalys, G., Sidlauskas, M. \& Marmaite, U. (2014) The prevalence of malocclusion and oral habits among 5-7-yearold children. Medical Science Monitor 20: 2036-2042.

Katri, K.N., Raija, L., Vuokko, L., Keski-nisula, L. \& Varrela, J. (2003) Occurrence of malocclusion and need of orthodontic treatment in early mixed dentition. American Journal of Orthodontics \& Dentofacial Orthopedics 124: 631-638.

Kenealy, P., Frude, N. \& Shaw, W. (1989) An evaluation of the psychological and social effects of malocclusion: some implications for dental policy making. Social Science \& Medicine 28: 583 591.

Kerosuo, H., Laine, T., Nyyssonen, V. \& Honkala, E. (1991) Occlusal characteristics in groups of Tanzanian and Finnish urban schoolchildren. Angle Orthodontist 61: 49-56.

Kerosuo, H. (2002) The role of prevention and simple interceptive measures in reducing the need for orthodontic treatment. Medical Principles and Practice 11 (Suppl): 16-21.

Krishna, R.G., Saritha, V. \& Suryaprakash, V.N. (2013) A study to determine the prevalence of malocclusion in primary dentition in suburban population in Chennai. Orthodontic Cyber Journal, 5, 1-58.

Larsson, E., Ogaard, B. \& Lindsten, R. (1992) Dummy- and finger-sucking habits in young Swedish and Norwegian children. Scandinavian Journal of Dental Research 100: 292-5.

Larsson, E. (1994) Artificial sucking habits: etiology, prevalence and effect on occlusion. International Journal of Orofacial Myology 20: 10-21.

Locker, D. (2000) Response and nonresponse bias in oral health surveys. Journal of Public Health Dentistry 60: 72-81.

Malandris, M. \& Mahoney, E.K. (2004) Aetiology, diagnosis and treatment of posterior cross-bites in the primary dentition. International Journal of Paediatric Dentistry 14: 155-166.

Mitchell, L. (2007) An Introduction to Orthodontics. 3rd edition, Oxford, Oxford University Press.

Moser, C. \& Kalton, G. (1971) Survey methods in social investigation, London, Heinemann.

Mugonzibwa, E.A., Eskeli, R., Kuijpers-Jagtman, A.M., Laine-Alava, M.T. \& Van't Hof, M.A. (2004) Occlusal characteristics during different emergence stages of the permanent dentition in Tanzanian Bantu and Finnish children. European Journal of Orthodontics 26: 251-260.

Ng'ang'a, P.M., Ohito, F., Ogaard, B. \& Valderhaug, J. (1996) The prevalence of malocclusion in 13to 15-year-old children in Nairobi, Kenya. Acta Odontologica Scandinavica 54: 126-30. 
Øgaard, B., Larsson, E. \& Lindsten, R. (1994) The effect of sucking habits, cohort, sex, intercanine arch widths, and breast or bottle feeding on posterior cross bite in Norwegian and Swedish 3-year-old children. American Journal of Orthodontic \& Dentofacial Orthopedics 106: $161-166$.

Onyeaso, C.O. \& Sote, E.O. (2001) Prevalence of oral habits in 563 Nigerian preschool children age 3-5 years. Nigerian Postgraduate Medical Journal 8: 193-195.

Onyeaso, C.O., Sote, E.O. \& Arowojolu, M.O. (2002) Need for preventive and interceptive orthodontic treatment in 3-5 year-old Nigerian children in two major cities. African Journal of Medical Sciences 31: 115-118.

Onyeaso, C.O. (2004) Prevalence of malocclusion among adolescents in Ibadan, Nigeria. American Journal of Orthodontics \& Dentofacial Orthopedics 126: 604-607.

Proffit, W.R., Fields, H.W. \& Sarver, D. (2012) Contemporary Orthodontics, $5^{\text {th }}$ Edition, Elsevier, 568 p.

Poyak, J. (2006) Effects of pacifiers on early oral development. International Journal of Orthodontics (Milwaukee Wis), 17: 13-16.

Quashie-Williams, R., Dacosta, O.O. \& Isiekwe, M.C. (2010) Oral habits, prevalence and effects on occlusion of 4-15-year-old school children in Lagos, Nigeria. Nigerian Postgraduate Medical Journal 17: 113-117.

Robke, F.J. (2008) Effects of nursing bottle misuse on oral health: prevalence of caries, tooth malalignments and malocclusions in north-German preschool children. Journal of Orofacial Orthopedics 69: 5-19.

Stahl, F. \& Grabowski, R. (2004) Malocclusion and caries prevalence: is there a connection in the primary and mixed dentitions? Clinical Oral Investigation 8: 86-90.

Thilander, B. \& Rönning, O. (1995) Introduction to Orthodontics. Stockholm: Gothia, pg. 76, 89-91.

Thilander, B., Pena, L., Infante, C., Parada, S.S. \& De Mayorga, C. (2001) Prevalence of malocclusion and orthodontic treatment need in children and adolescents in Bogota, Colombia. An Epidemiological study related to different stages of dental development. European Journal of Orthodontics 23: 153-167.

Trottman, A. \& Elsbach, H.G. (1996) Comparison of malocclusion in preschool black and white children. American Journal of Orthodontics \& Dentofacial Orthopedics 110: 69-72.

Varas, V.F., Gil, B.G. \& Izquierdo, F.G. (2012) Prevalence of childhood oral habits and their influence in primary dentition. Revista Pediatría de Atención Primaria 14: 13-20.

Viggiano, D., Fasano, D., Monaco, G. \& Strohmenger, L. (2004) Breast feeding, bottle feeding, and non-nutritive sucking; effects on occlusion in deciduous dentition. Archive of Diseases of Childhood 89: 1121-1123.

Wagner, Y. \& Heinrich-Weltzien, R. (2015) Occlusal characteristics in 3-year-old children--results of a birth cohort study. BMC Oral Health 7:15:94.

Warren, J.J., Levy, S.M., Nowak, A.J. \& Tang, S. (2000) Non-nutritive sucking behaviours in preschool children: A longitudinal study. Pediatric Dentistry 22: 187-191.

Warren, J.J. \& Bishara, S.E. (2002) Duration of nutritive and non-nutritive sucking behaviors and their effects on the dental arches in the primary dentition. American Journal of Orthodontics \& Dentofacial Orthopedics 121: 347-356.

Warren, J. J., Slayton, R.L., Bishara, S.E., Levy, S.M., Yonezu, T. \& Kanellis, M.J. (2005) Effects of non-nutritive sucking habits on occlusal characteristics in the mixed dentition. Pediatric Dentistry 27:445-50. 
Zhou, Z., Liu, F., Shen, S., Shang, L., Shang, L. \&Wang, X. (2016) Prevalence of and factors affecting malocclusion in primary dentition among children in Xi'an, China. BMC Oral Health 2: 16(1). 